DOI: $10.17805 /$ zpu.2018.3.16

\title{
Философско-исторические аспекты развития экологической культуры в Индии
}

\author{
Т. А. АРТАМОНОВА, С. И. БОНДАРЕНКО \\ АЛТАЙСКИЙ ГОСУДАРСТВЕННЫЙ АГРАРНЫЙ УНИВЕРСИТЕТ
}

В статье рассмотрены теоретические и практические вопросы развития экологической культуры в Индии. Актуальность этой темы обусловлена тем, что Индия на пороге XXI в. столкнулась с серьезными экологическими проблемами. Пути выхода из сложившейся ситуации лежат, в том числе, и в плоскости традиционной культуры. Насколько в традиционной культуре и философии Индии были развиты экологические мотивы? Могут ли они стать основой для развития и укрепления современной экологической культуры, так необходимой для решения насущных проблем сохранения природной среды?

Философско-религиозные основы индуизма содержат в себе мировоззренческий потенциал, способный помочь в разрешении современных экологических проблем. Ключевое понятие индийской философии «дхарма» является тем звеном, которое в настоящее время способно соединить религиозную и экологическую практику. Это мнение индийских исследователей, подтвержденное такими историческими примерами, как социальноэкологические движения «Чипко», «Аппико» и другие.

Сделаны выводы об уникальном опыте развития экологического движения в Индии и о необходимости широкого культурного контакта в этой области для решения общемировых экологических задач.

Ключевые слова: экологическая культура; экология; Индия; дхарма; индийская философия; индуизм; Чипко; Аппико

\section{ВВЕАЕНИЕ}

R ступая в XXI в., Индия столкнулась с серьезными экологическими проблемами. В Страна занимает третье место по объемам выбросов углекислого газа в атмосферу, и ситуация с каждым годом ухудшается. Утилизация и переработка отходов не менее важная проблема, а учитывая бурный рост населения, она принимает угрожающий характер. Недостаточная переработка электронного мусора, содержащего выброшенные электронные и прочие электрические устройства, а также их части, приводит к загрязнению воды, почвы вредными тяжелыми металлами, кислотами, что существенно ухудшает здоровье населения. Эрозия и опустынивание почв становятся для Индии настоящим экологическим бедствием. Эрозийными процессами охвачена почти половина территории Индии, в том числе примерно $60 \%$ пахотных и 95\% выгонно-пастбищных угодий (Индия: страна и ее регионы, 2010: 75). Нетронутые ландшафты сохранились только в труднодоступных горных областях и на сильно пересеченной местности. Аесом покрыто всего $20 \%$ территории, причем к категории «очень густой лес» принадлежит лишь 1,5\% (Гупта, 2012). Обезлесение горных склонов приводит к нарушению движения влажных воздушных масс, что в конечном счете способствует ускорению процесса таяния ледников. В свою очередь, сокращение площади гималайских ледников приведет к самым тяжелым последствиям как для жизни горной и предгорной биоты и населения прилегающих территорий, так и в целом повлияет на общее состояние мирового природно-экологического баланса.

Обзор современных экологических проблем Индии и поиск путей их решения заставляют задуматься о том, насколько в традиционной культуре и философии Индии были развиты экологические мотивы; могут ли они стать основой для развития 
и укрепления современной экологической культуры, так необходимой для решения насущных проблем сохранения природной среды. Поискам ответов на данные вопросы и посвящена настоящая статья.

\section{ЭКОАОГИЧЕСКИЕ МОТИВЫ АРЕВНЕИНАИЙСКИХ СВЯЩЕННЫХ ПИСАНИЙ И РАННИХ ФИАОСОФСКИХ ТЕКСТОВ}

Большинство древнеиндийских философских и религиозных систем были нацелены на постижение тайн бытия и проникновение в глубины человеческого духа. Именно метафизичность и психологизм были ведущими чертами интеллектуальной жизни индийцев, порождая некую оторванность от природных реалий и физической действительности. С. Радхакришнан в своем фундаментальном труде «Индийская философия» пишет, что «наслаждение познанием является одним из наиболее чистых наслаждений, доступных человеку, и страсть индийцев к познанию ярким пламенем горит в их умах» (Радхакришнан, 1993: 12). Но этот огонь познания связан прежде всего с духовной сферой жизни космоса и человека. Радхакришнан определяет это как спиритуалистический характер индийской философии: «Именно спиритуализм, а не развитая Индией грандиозная политическая структура и социальная организация, дал ей возможность противостоять разрушительному действию времени и превратностям истории. <...> В Индии была решена трудная задача - вызвать у народа интерес к метафизике» (там же: 14).

Ааже религиозные культы индуизма, связанные с почитанием природных объектов (рек, озер, гор, Солнца, Ауны, огня, грозы и т. п.), базировались на признании главенства духовной составляющей природы. Необходимость естественно-научного познания природной среды, ее освоения и защиты, что является отправной точкой формирования экологического мировоззрения, не была ярко выраженной. Это, конечно, не значит, что в Аревней Индии не развивалось естественно-научное знание, оно было достаточно широко распространено. К основным достижениям естественных наук Аревней Индии можно отнести знания в области астрономии, физиологии, зоологии, ботаники, геологии. Значительны достижения индийцев в химии. Они знали состав руд и минералов, умели изготавливать сплавы, стекло, искусственные драгоценные камни, ароматические эссенции и яды, делали прочные растительные и минеральные красители. В философских и научных трактатах ученые разрабатывали идеи о том, что все вещества в природе состоят из «ану» - атомов. Индийцы знали, что Земля вращается вокруг Солнца и своей оси (Ванина, 2017: Электронный ресурс).

Современные исследователи выделяют некоторые экологические мотивы древнеиндийских священных писаний и ранних философских текстов. Так, анализируя «Артхашастру», они делают акцент на описании суровых наказаний и штрафов за рубку ветвей или деревьев. Изучая эдикты императора Ашоки, исследователи обращают внимание на то, что уже в III в. до н. э. он запретил охоту, составив перечень птиц и животных, которых запрещается уничтожать. В. Нараянан цитирует несколько отрывков из Рамаяны и Пуран, в которых имеются такие утверждения, как «одно дерево равно десяти сыновьям» (Narayanan, 1997: Электронный ресурс).

Но не все исследователи придерживаются той точки зрения, что древнеиндийская философия имеет экологическую компоненту, поэтому вопрос о влиянии различных философских систем, религиозных культов, народных традиций Индии на формирование экологической культуры населения остается дискуссионным. 


\section{«АХАРМА» КАК КАЮЧЕВОЕ ПОНЯТИЕ \\ ТРААИЦИОННОЙ ИНАИЙСКОЙ КУ АЬТУРЫ}

Аостаточно обширный обзор вклада индуизма в решение этой проблемы дает доктор Панкадж Ажайн в работе «Ахарма и экология» (Jain, 2011). «Насколько поклонение индусов природе подталкивает их к осознанным экологическим действиям, отвечающим современной ситуации?» - вот основной вопрос, на который автор ищет ответ. Во введении он пишет, что традиционная религия может многому научить нас, как уважать или даже почитать природу. Но теперь, когда природа - мощный, бесконечный источник всех наших жизней - стала хрупкой и загрязненной, необходимы значительные сдвиги религиозного понимания и практики (Jain, 2011: 2). Аоктор Ажайн выбрал для исследования три деревенские религиозные общины Раджастхана и Гуджарата: общину, основанную движением Свадхьяя, сообщество Бишной и племя Бхил. Эти общины не только почитают природу как источник духовного очищения и просветления, но также пытаются защитить и сохранить ее на основе своих верований и религиозной практики. Появление сообщества Бишной и племени Бхил относится к средневековым временам штата Раджастхан. Авижение Свадхьяя возникло в середине XX в. в штате Гуджарат в качестве «нового религиозного движения». Таким образом, ни одна из этих групп не возникла как реакция на «глобальное потепление» или «сохранение биоразнообразия», что принято рассматривать как экологически обоснованные причины. Тем не менее пример экологических действий этих трех общин оценивается автором как наиболее эффективный по сравнению с большинством правительственных инициатив. Рассмотрим подробнее эти примеры.

Представители движения Свадхьяя имеют много экологических достижений на своем счету: они построили водосборные сооружения в Гуджарате и в других штатах, вырастили сады в засушливых районах Индии. Пышные заросли манго зазеленели там, где местные жители уже и не надеялись что-то вырастить. Представители Свадхьяя относятся к этим деревьям как к храмам, так как для них социальная и природоохранная деятельность - это лишь формы выражения преданности Богу. Они не считают себя экологами и подчеркивают, что главной целью их деятельности является преобразование человеческого общества на основе концепции Упанишад: так как Всевышний пребывает в каждом человеке, то любой человек должен развивать чувство духовного уважения к себе независимо от материального и социального статуса. Иидеры Свадхьяя призывают своих последователей строить жизнь на идее «братства людей под опекой Бога-Отца», а для этого приемлемы любые виды помощи ближнему, в том числе и по охране и восстановлению природных ресурсов, что так актуально для сельских территорий Индии. Аля них экологическая работа - необходимая часть соблюдения дхармы.

Представителей общины Бишной часто относят к «зеленой вере». Аидер общины Ажамбхешвар (Jambheśvara), живший на рубеже XV-XVI вв. (1451-1536), после долгих лет активной медитации и аскезы решил перейти к духовному преобразованию местного сообщества, которое в то время уже столкнулось с серьезными экологическими проблемами, характерными для штата Раджастхан. Он разработал 29 правил, восемь из которых связаны с защитой природы. Эти правила включают, в частности, запрет на убийство животных, запрет на ношение синей одежды, краску для которых получают из местной растительности. Ажамбхешвар в XV в. был, вероятно, первым индийским гуру, который подчеркнул роль экологического знания в своем учении. Он запрещал наносить вред деревьям или животным и призывал к вегетарианству. Восемь 
правил также предусматривали сохранение биоразнообразия и поощряли гуманное животноводство. Они включали в себя отказ от стерилизации быков и воздержание от жертвоприношений козлов в храмах, запрет на убийство животных и вырубку любых видов деревьев, обеспечение защиты всех форм жизни. Последователи даже осматривали дрова, чтобы убедиться в отсутствии мелких насекомых, прежде чем сжигать их в очагах. Община вырастила огромный сад, который до сих пор помогает сохранить источники питьевой воды. Кроме этого, сухие листья и птичий помет служат природными удобрениями для выращивания сельхозпродукции.

Главная экологическая победа общины Бхил - это сохранение священных рощ в районах Бансвара и Аангарпур. Их удалось отстоять, в то время как на остальной территории Южного Раджастхана священные рощи в первой половине ХХ в. интенсивно вырубались. В целом Индия сегодня имеет около 13720 священных рощ в 19 штатах. В таких штатах, как Керала, Махараштра, Андхра-Прадеш и Тамилнад, расположено максимальное количество священных рощ, которые богаты редкими и эндемичными видами растений и животных. Эти территории сегодня охраняются на основе как религиозных традиций, так и современных принципов устойчивого развития природных ресурсов. Сообщество Бхил добилось того, что священные рощи Раджастхана на основе местного природоохранного законодательства официально отнесены к высшему рангу особо охраняемых территорий сообществ.

Что же явилось мировоззренческой основой этих экологических инициатив?

Панкадж Ажайн в качестве основы для исследования экологической этики и религиозной жизни индийских жителей предлагает использовать глубоко укоренившееся в местном сознании понятие дхармы. «Такие категории, как “религия”, “этика” и “экология", работают хорошо для современных городских жителей Индии. Тем не менее для миллионов сельских жителей “дхарма” объединяет и синтезирует их образ жизни с экологической этикой» (Jain, 2011: 6). Аля каждой группы населения, будь то каста, община, род, семья, дхарма имеет свою специфическую форму. Ахарма, как проявление экологического долга, по мнению автора, в индийской традиции представлена двумя моделями: «благочестивой» и «аскетической». Эти две модели поведения основываются на древнем конфликте «змеи - мангуста»: это специфические формы сознания и поведения, отличающие обычных жителей и аскетов-подвижников. Обычные жители для поддержания благочестия выполняют прежде всего предписанные им традицией ритуальные мероприятия и обряды, тогда как подвижники живут по особо строгим ограничительным нормам и правилам.

Какая же из этих моделей более эффективна для формирования экологических принципов поведения?

Прежде чем представить свою точку зрения, П. Ажайн приводит мнение других исследователей, которые выступают с критикой «благочестивой модели». По их мнению, она не способна повлиять на традиционное мировоззрение и поведение населения Индии и направить его на решение экологических проблем, так как религиозное сознание полностью исключает воздействие физических неблагоприятных факторов, все сводя лишь к метафизическим причинам. Так, К. Аллеи в качестве примера приводит описание ситуации в Бенаресе, когда верующие знали о том, что река Ганг катастрофически загрязняется, но для них Ганга, будучи чистой богиней, никогда не может стать грязной и непригодной для проведения ритуалов. По их мнению, Богиня Ганга способствует очищению как самой реки, так и верующих. Таким образом, делает заключение исследователь, «благочестивая модель» поведения может иногда пре- 
вращаться в «услужливую модель», т. е. исключать активную позицию по отношению к насущным экологическим проблемам (Jain, 2011: 8).

Сторонник «аскетической модели»- Чаппле (ученый джайнистской традиции) ратует за то, что только принцип ненасилия в отношении к животным, деревьям и к личности в сочетании с нестяжательством может привести к экологически осознанному поведению, восстановлению и поддержанию экологического баланса. Чаппле представляет Махатму Ганди как пример человека, который лично максимально сократил «жизненные потребности» и свое имущество, таким образом, реализовав нормы экологической этики. Согласно Чаппле, Ганди и другие, кто живет по аскетическим и йогическим принципам, могут служить образцом модели ограничения. Чаппле отмечает, что джайны, следуя своим аскетическим ценностям, приводили в действие «социальную совесть»: они убедили первых буддистских монахов прекратить их скитания во время сезона дождей, чтобы избежать уничтожения многочисленных насекомых и растений, которые развиваются во время муссонов (Jain, 2011: 8). Сообщество джайнов разработало и реализовало мирские правила для обеспечения интеграции ненасильственных ценностей в трудовую деятельность. Ажайны выступили против ядерного оружия. Руководитель секты Терапанти Шветамбара, Ачарья Тулси, занял активную общественную позицию по многочисленным экологическим вопросам.

Панкадж Ажайн согласен с тем, что, следуя «аскетической модели», можно прийти к снижению своих бытовых потребностей и, таким образом, ограничить нагрузку на природу. Тем не менее в такой стране, как Индия, сегодня внимание и предпочтения общества сводятся не к ограничению потребления, а к его увеличению. Население интенсивно развивающихся городов охвачено растущим потреблением. Это одна из характерных черт всей современной техногенно-потребительской цивилизации, а не только Индии. Торговая реклама, государственная идеология, работа СМИ - все пропитано идеей необходимости безмерного увеличения потребления и уровня комфорта как нормы современной «достойной жизни». Поэтому призывать средний класс населения к ограничению потребления малоэффективно. Пропагандировать же аскетический образ жизни для малоимущих классов и вовсе неприемлемо, так как их уровень потребления и без того крайне низок. Поэтому автор приходит к выводу, что необходимо создать синтетическую модель, используя идеи как аскетизма, так и религиозного благочестия. По его мнению, примером может служить деятельность таких гуру и лидеров религиозных движений, как Ажамбхешвар, Ганди, Бахугуна и Атхавале, которые в значительной мере способствовали развитию экологического сознания в Индии.

\section{РАЗВИТИЕ ЭКОАОГИЧЕСКИХ ИНИЦИАТИВ В ИНАИИ: ИСТОРИЧЕСКИЕ ПРИМЕРЫ}

В XVIII в. 363 представителя Бишнои пожертвовали своими жизнями, чтобы защитить дерево пустыни - кхеджари - от солдат раджи Ажодхпура. Сегодня у индийского правительства есть особая экологическая награда в честь Амриты Аеви, женщины Бишнои, которую можно отнести к первым экологическим мученикам Индии.

Массовое экологическое движение в стране началось с движения «Чипко» («Обними дерево»). В 1973 г. в городе Гоупшваре в области Шамоли жители образовали человеческую цепь и обняли деревья, отмеченные для рубки дровосеками с близлежащей фабрики, производящей спортинвентарь. В других городах стали происходить аналогичные случаи, когда лесозаготовители хотели срубить деревья, пользуясь по- 
становлениями правительственного лесного департамента. В 1974 г. женщины деревни Рени, возле Йошимата в Гималаях, бросили вызов лесозаготовителям, обняв деревья и вынудив промышленников уйти. С тех пор «Чипко Андолан» (движение защиты деревьев, обнимая их) стало народным экологическим движением (Омвед, 1992).

В других районах Индии стали возникать движения, основанные на идеях «Чипко». Это «Аппико» (по защите деревьев в штате Карнатака), «Спасти Молчаливую долину» в Керале и др. В результате, в 1970-е годы лесное хозяйство Индии перешло от этапа, преследующего почти исключительно коммерческие цели, к этапу, уделяющему большее внимание экологической роли лесов, ценности биоразнообразия и участию народа в их использовании (Гупта, 2012: 137).

Впоследствии движение «Обними дерево» приобрело более широкий размах. Крестьяне стали самостоятельно сажать деревья, бороться с пьянством, выступили в поддержку полной занятости. В результате социально-экологической деятельности были сформулированы положения, согласно которым восстановление лесов необходимо было поставить под контроль местных органов власти, а породы деревьев подбирать исходя из потребностей в топливе, продуктах питания, а не из их ценности для промышленного производства (Омвед, 1992: 291).

Это движение, возникнув еще в XVIII в., проделало путь от кампании по защите места проживания в нескольких деревнях современного штата Уттаркханд до крупнейшего общеиндийского протеста. По мнению С. И. Аунева, индийское общество считает, что именно эта лесная сатьяграха способствовала укреплению гражданского общества и заложила основы экологического движения в стране (Аунев, 2015: 203). Сатьяграха означает «настойчивость в поиске правды». В данном контексте термин «лесная сатьяграха» означает «настойчивость в поиске правды, касающейся прав деревьев» (Авиведи, де Сильва, Иззи Аин, 1994: Электронный ресурс).

Анализируя специфику экологического движения в Индии и влияние на его формирование религиозных ценностей, Панкадж Ажайн отмечает важный момент, на который обращают внимание и другие исследователи: әкологическая деятельность не воспринимается самими членами обшин как иеленаправленная зашита окружаюшей средь, а является проявлением их религиозных обязанностей. Религиозные ценности способствуют косвенному развитию экологической культуры населения Индии. Примером могут служить уже перечисленные движения «Чипко» и «Аппико», представители которых во время экологических акций читали тексты Бхагавадгиты и Пуран, что красноречиво говорит о религиозной основе экологических действий. Поэтому доктор Ажайн в своем исследовании и делает упор на понятии дхармы как основы именно религиозного благочестия, но в то же время способного повлиять на экологическую активность населения. «Изучая опыт общин Свадхьяя и Бишнои, я часто приходил к мнению, что движение в защиту окружающей среды - просто побочный продукт их традиционного уважения биобожественности. Аля них сохранение биоразнообразия - вторично по отношению к задаче выполнения их дхармы» (Jain, 2011: 10).

В плане сочетания религиозных традиций и экологических задач интересен пример деятельности служителей храма Тирупати в штате Андхра-Прадеш. Это один из самых богатых храмов Индии, который собирает пожертвований в несколько сотен миллионов рупий каждый год. Примечательно то, что этот храм изменил свой обычный прасад ${ }^{1}$ из конфет на небольшие растения, которые даются паломникам для посадки. Это привело к тому, что посадки из нескольких миллионов растений останови- 
ли вырубку леса в горах близ Тирупати. Аналогичная инициатива проводится представителем Института гималайской әкологии Г. Б. Пантом, который работает с храмом Бадринатх. Его ученые выращивают саженцы, священники благословляют их и распространяют как прасад для паломников.

\section{ЗАКАЮЧЕНИЕ}

Таким образом, можно сделать вывод о том, что для большинства жителей прежде всего сельской Индии традиционная религиозная культура в ее широком понимании является основой для развития и укрепления современной экологической культуры. И в работе Аж. Панкаджа при анализе экологических действий индусов не случайно сделан акцент на дхарме как одном из ключевых философско-религиозных понятий. Макаранд Паранджапе, исследующий движение Свадхьяя, также пишет: «...дхармовое мировоззрение - это то, что сообщается чувством космического морального порядка, порядка, включающего сообщество и личность. Я считаю, что Индия - не светское общество, а общество дхармы» (Paranjape, 1996: Электронный ресурс). Религиозными мотивами в Индии пропитана не только экологическая деятельность, но и многие другие сферы жизни народа. Об этом свидетельствуют результаты соцопроса, проведенного в 2016-2017 гг. российскими учеными под руководством профессора Ю. В. Попкова в рамках проекта «Алтай и Гималаи как уникальные культурно-биосферные регионы Евразии: поиск общих ценностей, эколого-экономических стратегий и социокультурных параллелей» (Алтай и Гималаи ... , 2017: 97-112).

Конечно, при решении экологических задач современности только с опорой на религиозные ценности неизбежно произойдет сужение спектра этих задач. Вне круга религиозных интересов вполне могут оказаться проблемы изменения климата, загрязнения окружающей среды или снижения биоразнообразия. Необходимы более широкие подходы, имеющиеся в мировой практике, а также более интенсивное использование средств защиты окружающей среды из арсенала научной экологии. С другой стороны, уникальный пример Индии, использующей традиционные религиозные мотивы для решения экологических проблем, также может обогатить опыт других стран в сфере развития экологической культуры.

\section{ПРИМЕЧАНИЕ}

1 Прасад («божественный дар») в индуизме - подношение божеству, которое после службы в храме раздается верующим как символ божественной благодати и благословения. В качестве прасада обычно используются сладости, фрукты, орехи, цветы.

\section{СПИСОК АИТЕРАТУРЫ}

Алтай и Гималаи как уникальные культурно-биосферные регионы Евразии (2017)/ под ред. А. В. Иванова, И. В. Фотиевой. Барнаул : РИО Алтайского ГАУ. 336 с.

Ванина, Е. Ю. (2017) Научные достижения Аревней Индии [Электронный ресурс] // Наука и жизнь. № 3. URL: https://www.nkj.ru/archive/articles/14930/ (дата обращения: 26.02.2018).

Авиведи, О., де Сильва, А., Иззи Аин, М. (1994). Экологические и этические взгляды индуизма, буддизма и ислама [Электронный ресурс] // Киевский эколого-культурный центр. URL: http://www.ecoethics.ru/old/m2.06/x20.html (дата обращения: 26.02.2018). 360 c.

Индия: страна и ее регионы (2010) / отв. ред. Е. Ю. Ванина. 3-е изд. М. : Эдиториал УРСС.

Иунев, С.И. (2015) Социальные протесты в Индии // Вестник МГИМО. Политические науки. № 4 (43). С. 201-205. 
Омвед, Г. (1992) Экологическое движение крестьян // Великий незнакомец: крестьяне и фермеры в современном мире : пер. с анг. / сост. Т. Шанин ; под ред. А. В. Гордона. М. : Прогресс. 432 с. С. $290-294$.

Радхакришнан, С. (1993) Индийская философия : в 2 т. М. : Миф. Т. 1. 624 с.

Гупта, Хеман К. (2012) Эколого-культурный ландшафт Гималаев в штате Химачал-Прадеш: связь традиционных знаний о лесе с научным управлением лесами // Алтай - Гималаи: два устоя Евразии / под ред. С. П. Бансал и др. Барнаул : Изд-во АГАУ. С. 133-153.

Jain, Pankaj (2011) Dharma and ecology of Hindu communities: sustenance and sustainability (Ashgate new critical thinking in religion, theology and biblical studies). University of North Texas, USA. 228 p.

Narayanan, V. (1997) "One Tree is Equal to Ten Sons": Hindu Responses to the Problems of Ecology, Population and Consumption [Электронный pecypc]// Journal of American Academy of Religion. Vol. 65. No. 2. P. 291-332. URL: https://www.jstor.org/stable/1465767?seq=1\#page_scan_ tab_contents (дата обращения: 26.02.2018).

Paranjape, Makarand (1996) Spiritual Sites as Sources of Social Transformation: Lessons from Svadhyaya [Электронный ресурс]// Swadhyay Parivar. URL: http://www.infinityfoundation.com/ mandala/s_es/s_es_paran_lessons_frameset.htm (дата обращения: 26.02.2018).

Аата поступления: 09.04.2018 г.

\section{PHILOSOPHICAL AND HISTORICAL ASPECTS OF DEVELOPMENT \\ OF ECOLOGICAL CULTURE IN INDIA \\ T. A. Artamonova, S. I. Bondarenko \\ ALtaI State AgraRian UNIVERSITY}

In the article theoretical and practical questions of development of ecological culture in India are considered. Relevance of this subject is caused by the fact that India on the dawn of XXI centuries faced serious environmental problems. Ways of an exit from this situation lie, among other things, in the plane of traditional culture. The main thesis of this article is that philosophical and religious basis of Hinduism comprise the world outlook potential capable to help with permission of environmental problems. The key concept of the Indian philosophy «Dharma» is the link which is capable to connect religious and ecological practice. This opinion of the Indian researchers confirmed with such historical examples as the social-and-ecological movement «Chipko», «Appiko» and others is subjected in article of a philosophical reflection.

The objective of this research is in finding answers to the following questions: 1 ) to what extent ecological motives were developed in traditional culture and philosophy; 2) whether they can become a basis for development and strengthening of modern ecological culture, so necessary for the solution of pressing problems and preservation of the environment. In the final of the article conclusions are drawn on unique experience of development of the ecological movement in India and on need of broad cultural contact for this area for the solution of universal ecological tasks.

Keywords: ecological culture, Indian traditions, Dharma, Indian philosophy, Hinduism, Chipco movement, Appiko movement, technogenic and consumer civilization.

\section{REFERENCES}

Altaj i Gimalai kak unikal'nye kul'turno-biosfernye regiony Evrazii (2017) / ed. by A. V. Ivanov and I. V. Fotieva. Barnaul, RIO Altajskogo GAU. 336 p. (In Russ.).

Vanina, E. Yu. (2017) Nauchnye dostizheniya Drevnej Indii. Nauka i zhizn', no. 3 [online] Available at: https://www.nkj.ru/archive/articles/14930/ (access date: 26.02.2018). (In Russ.).

Dvivedi, O., de. Sil'va, L. and Izzi Din, M. (1994). EHkologicheskie i ehticheskie vzglyady induizma, buddizma i islama. Kievskij ehkologo-kul'turnyj centr [online] Available at: http://www. ecoethics.ru/old/m2.06/x20.html (access date: 26.02.2018). (In Russ.).

Indiya: strana i ee regiony (2010) / ed. by E. Yu. Vanina. 3nd ed. Moscow, Ehditorial URSS. 360 p. (In Russ.). 
Lunev, S. I. (2015) Social'nye protesty v Indii. Vestnik MGIMO. Politicheskie nauki, no. 4 (43), pp. 201-205. (In Russ.).

Omved, G. (1992) Ekologicheskoe dvizhenie krest'yan. Velikij neznakomec: krest'yane i fermery v sovremennom mire : transl. from Engl. / comp. by T. Shanin ; ed. by A. V. Gordon. Moscow, Progress. 432 p. Pp. 290-294. (In Russ.).

Radhakrishnan, S. (1993) Indijskaya filosofiya : in 2 vol. Moscow, Mif. Vol. 1. 624 p. (In Russ.).

Gupta, Heman K. (2012) Ekologo-kul'turnyj landshaft Gimalaev v shtate Himachal-Pradesh: svyaz' tradicionnyh znanij o lese s nauchnym upravleniem lesami. In: Altaj - Gimalai: dva ustoya Evrazii / ed. by S. P. Bansal et al. Barnaul, Izd-vo AGAU. Pp. 133-153. (In Russ.).

Jain, P. (2011) Dharma and ecology of Hindu communities: sustenance and sustainability (Ashgate new critical thinking in religion, theology and biblical studies). University of North Texas, USA. $228 \mathrm{p}$.

Narayanan, V. (1997) "One Tree is Equal to Ten Sons": Hindu Responses to the Problems of Ecology, Population and Consumption. Journal of American Academy of Religion, vol. 65, no. 2, pp. 291-332 [online] Available at: https://www.jstor.org/stable/1465767?seq=1\#page_scan_tab_ contents (access date: 26.02.2018).

Paranjape, M. (1996) Spiritual Sites as Sources of Social Transformation: Lessons from Svadhyaya. Swadhyay Parivar [online] Available at: http://www.infinityfoundation.com/mandala/s_es/s_es_ paran_lessons_frameset.htm (access date: 26.02.2018).

Submission date: 09.04.2018.

Артамонова Татьяна Александровна - кандидат философских наук, доцент, доцент кафедры философии Алтайского государственного аграрного университета. Адрес: 656049, Россия, г. Барнаул, пр. Красноармейский, А. 98. Тел.: +7 (3852) 20-33-47. Эл. адрес: art-katun@mail.ru

Бондаренко Светлана Ивановна - кандидат исторических наук, доцент, доцент кафедры истории Алтайского государственного аграрного университета. Адрес: 656049, Россия, г. Барнаул, пр. Красноармейский, д. 98. Тел.: +7 (3852) 20-33-48. Эл. адрес: bonsvet@bk.ru

Artamonova Tatiana Alexandrovna, Candidate of Philosophy, Associate Professor, Associate Professor of Philosophy Department, Altai State Agrarian University. Postal address: 98 Krasnoarmeyskaya, Barnaul,656049, Russia. Tel.: +7 (3852) 62-80-59.E-mail: art-katun@mail.ru

Bondarenko Svetlana Ivanovna, Candidate of History, Associate Professor, Associate Professor of History Department, Altai State Agrarian University. Postal address: 98 Krasnoarmeyskaya, Barnaul, 656049, Russia. Tel.: +7 (3852) 20-33-48. E-mail: bonsvet@bk.ru 